\title{
In silico identification and docking-based drug repurposing against the main protease of SARS-CoV-2, causative agent of COVID-19
}

Yogesh Kumar ${ }^{1 \# *}$, Harvijay Singh ${ }^{2 \# *}$

${ }^{1}$ Department of Metabolic \& Structural Bilogy, CSIR-Central Institute of Medicinal \& Aromatic Plants, Lucknow (226015) India.

${ }^{2}$ Department of Biochemistry, Molecular Biology \& Biophysics, University of Minnesota, Minneapolis MN (55455) USA

${ }^{\#}$ Contributed equally to this article

*Corresponding authors:

Dr. Yogesh Kumar; Email: kumar.yogesh601@gmail.com

Dr. Harvijay Singh; Email: hsingh@umn.edu

\begin{abstract}
The rapidly enlarging COVID-19 pandemic caused by novel SARS-coronavirus 2 is a global public health emergency of unprecedented level. Therefore the need of a drug or vaccine that counter SARS-CoV-2 is an utmost requirement at this time. Upon infection the ssRNA genome of SARS-CoV-2 is translated into large polyprotein which further processed into different nonstructural proteins to form viral replication complex by virtue of virus specific proteases: main protease (3-CL protease) and papain protease. This indispensable function of main protease in virus replication makes this enzyme a promising target for the development of inhibitors and potential treatment therapy for novel coronavirus infection. The recently concluded $\alpha$-ketoamide ligand bound X-ray crystal structure of SARS-CoV-2 M pro (PDB ID: 6Y2F) from Zhang et al. has revealed the potential inhibitor binding mechanism and the determinants responsible for involved molecular interactions. Here, we have carried out a virtual screening and molecular docking study of FDA approved drugs primarily targeted for other viral infections, to investigate their binding affinity in $\mathrm{M}^{\text {pro }}$ active site. Virtual screening has identified a number of antiviral drugs, top ten of which on the basis of their bending energy score are further examined through
\end{abstract}


molecular docking with $\mathrm{M}^{\text {pro }}$. Docking studies revealed that drug Lopinavir-Ritonavir, Tipranavir and Raltegravir among others binds in the active site of the protease with similar or higher affinity than the crystal bound inhibitor $\alpha$-ketoamide. However, the in-vitro efficacies of the drug molecules tested in this study, further needs to be corroborated by carrying out biochemical and structural investigation. Moreover, this study advances the potential use of existing drugs to be investigated and used to contain the rapidly expanding SARS-CoV-2 infection.

\section{Introduction}

The ongoing and rapidly spreading outbreak of the Covid-19 pandemic, which is being caused by the highly contagious and pathogenic SARS-Coronavirus-2 (SARS-CoV-2), has endangered the global public health and alarmed the scientific community at an unprecedented magnitude. The novel SARS-CoV-2 was first reported to have emerged in the live wildlife market in the Wuhan region of Hubei province, where it has caused mystic pneumonia-like respiratory illnesses in the human population of the area $(1,2)$. Later, the virus has made its way under extensive and fast-paced human travel to other geographic locations in the world such as Japan, Australia, Southeast Asian countries, Western European countries, Middle Eastern Countries, and finally to USA, Canada, and India. According to data presented by the World Health Organization (WHO), as of March 23, 2020, the virus has infected more than 693,224 people in more than 190 countries around the world including a staggering 33,106 deaths, with a cumulative mortality rate of $>4.7 \%$ (3). Despite the instantaneous, collaborative, and monumental research efforts from the scientific community around the globe, no vaccine or therapeutic intervention could be developed to cure or mitigate the Covid-19 so far. The treatment of severely ill patients has been limited to the use of prophylactic and symptomatic management. In contrast, the prevention of disease has been only effective through strong and preemptive measures from health organizations and governmental authorities such as the sought outs for practicing social distancing, maintaining respiratory hygiene, and impositions of public curfews and state-wide lockdowns.

Coronaviruses (CoVs), which belong to family Coronaviridae of viruses, constitute an essential class of pathogens for humans and other vertebrates (4). Before the current SARS-CoV2 induced pathogenesis, only six of the CoVs were known to cause mild to severe illnesses in humans. HCoV-229E, HCoV-OC43, HCoV-NL63, and HKU1, which fall in genera 
alphacoronavirus, cause milder upper respiratory disease in adults, and sometimes can also cause severe infection in infants and young children. Whereas the betacoronaviruses like SARS$\mathrm{CoV}$ (severe acute respiratory syndrome coronavirus; which has triggered an epidemic in China during 2002-03) and MERS-CoV (Middle East respiratory syndrome coronavirus; an etiological agent of middle East coronavirus epidemic of 2012) have potential to cause infection in lower respiratory tract along with cough $\&$ fever and triggers severe respiratory illness in humans $(5,6)$. The causative agent of the current outbreak, SARS-CoV-2, also belongs to betacoronavirusesand is closely related to SARS-CoV with an overall genomic sequence similarity of $>79 \%$ (7).

The virion of SARS-CoV-2 is consists of crown-shaped peplomers, $80-160 \mathrm{~nm}$ in diameter, and consists of a $\sim 30 \mathrm{~kb}$ long single-stranded RNA molecule of positive polarity with 5' cap and 3' Poly-A tail (8). The RNA genome is composed of at least six open reading frames (ORFs) of which the first ORF (ORF1a/b) makes up the 5'two-third and encodes two polypeptides ppla and pplab both of which furthermore leads to the production of 16 nonstructural proteins (nsPs). Other ORFs that make up the remaining one-third of the viral genome give rise to the production of four main structural factors of the virion: Spike protein $(\mathrm{S})$, Envelope protein (E), Membrane protein (M) and Nucleocapsid protein (N) (9).

The virus uses the heterotrimeric Spike (S) protein, which consists of S1 and S2 subunit, on its surface to interacts with the ACE2 (angiotensin-converting enzyme 2) cellular receptor, abundantly expressed on many cell types in human tissues (10). Upon internalization into the cell, genomic RNA is used as a template for direct translation of two polyprotein ppla and pplab which encodes a number of crucial nonstructural proteins (nsPs) including two proteases; Chymotrypsin-like protease $\left(3 \mathrm{CL}^{\mathrm{pro}}\right)$ or main protease $\left(\mathrm{M}^{\mathrm{pro}}\right)-\mathrm{nsP} 5$ and a papain like protease $\left(\mathrm{P}^{\mathrm{pro}}\right)$-nsP3, both of which processes the polypeptide ppla and pplab in a sequence specific manner to produce 16 different nsPs $(11,12)$. The papain protease processes the polyprotein to generate nsP1-4 while the $\mathrm{M}^{\mathrm{pro}}$ operates at as many as 11 cleavage sites by specifically recognizing the sequence Leu-Gln*Ser-Ala-Gly (* marks the cleavage site) to generate rest of the critical nsPs including helicase, methyltransferase, and RNA dependent RNA polymerase (RdRp) all of which play a critical role in the viral infection cycle by forming a replicationtranscription complex (RTC) (13). Therefore, the main protease constitutes a major and attractive drug target to block the production of nonstructural viral components and thereby to hamper the replication event of the virus life cycle. Additionally, no human protease with similar cleavage 
specificity is known to rule out the possibility of cellular toxicity upon the potential inhibition of main viral protease.

In recent years drug repurposing screens have emerged as a resourceful alternative to fasten the drug development process against rapidly spreading emerging infections such as the one of SARS-CoV-2 $(14,15)$. The approach of drug repurposing has successfully led to the discoveries of potential drug candidates against several diseases such as Ebola disease, hepatitis $\mathrm{C}$ virus, and zika virus infection (16-19). In the present study, we have applied the approach of in silico virtual screening and protein-ligand docking of a spectrum of Food and Drug Administration (FDA) - approved antiviral drugs against SARS-CoV-2 $\mathrm{M}^{\text {pro }}$. To this end a recently elucidated X-ray crystal structure of SARS-CoV-2 Mpro (PDB ID: 6Y2F) which have been shown to harbor an $\alpha$-ketoamide as a potent inhibitor in the enzyme's active site, was chosen and screened for a number of FDA approved antiviral drugs to simulate the $\mathrm{M}^{\text {pro }}-\alpha$ ketoamide interactions and thereby blocking the active pocket (20). The crystal structure of SARS-CoV-2 $\mathrm{M}^{\text {pro }}$ in apo form (PDB ID: 6Y2E) and $\alpha$-ketoamide bound form (PDB ID: 6Y2F) shows that the protein makes a crystallographic dimer composed of two monomers of identical conformations. Each protomer furthermore is made up of three domains. The interface of domain I and domain II form the active site of the protein, which is composed of a Cys ${ }^{145}-\mathrm{His}^{41} \mathrm{dyad}$ where $\alpha$-ketoamide derivative 13b is bound (Fig.1A). The uniquely globular domain III is linked to domain II through a linker region and deemed essential for the catalytic activity of this chymotrypsin-like protease $(20,21)$. The $\alpha$-ketoamide derivative $13 \mathrm{~b}$ is shown bound in the active site and is stabilized by a number of interactions with the active site residues $\mathrm{His}^{41} \&$ Cys $^{145}$ and adjacent residues in substrate binding cleft such as Gly ${ }^{143}$ and $\operatorname{Ser}^{144}$ (20) (Fig.1B). 

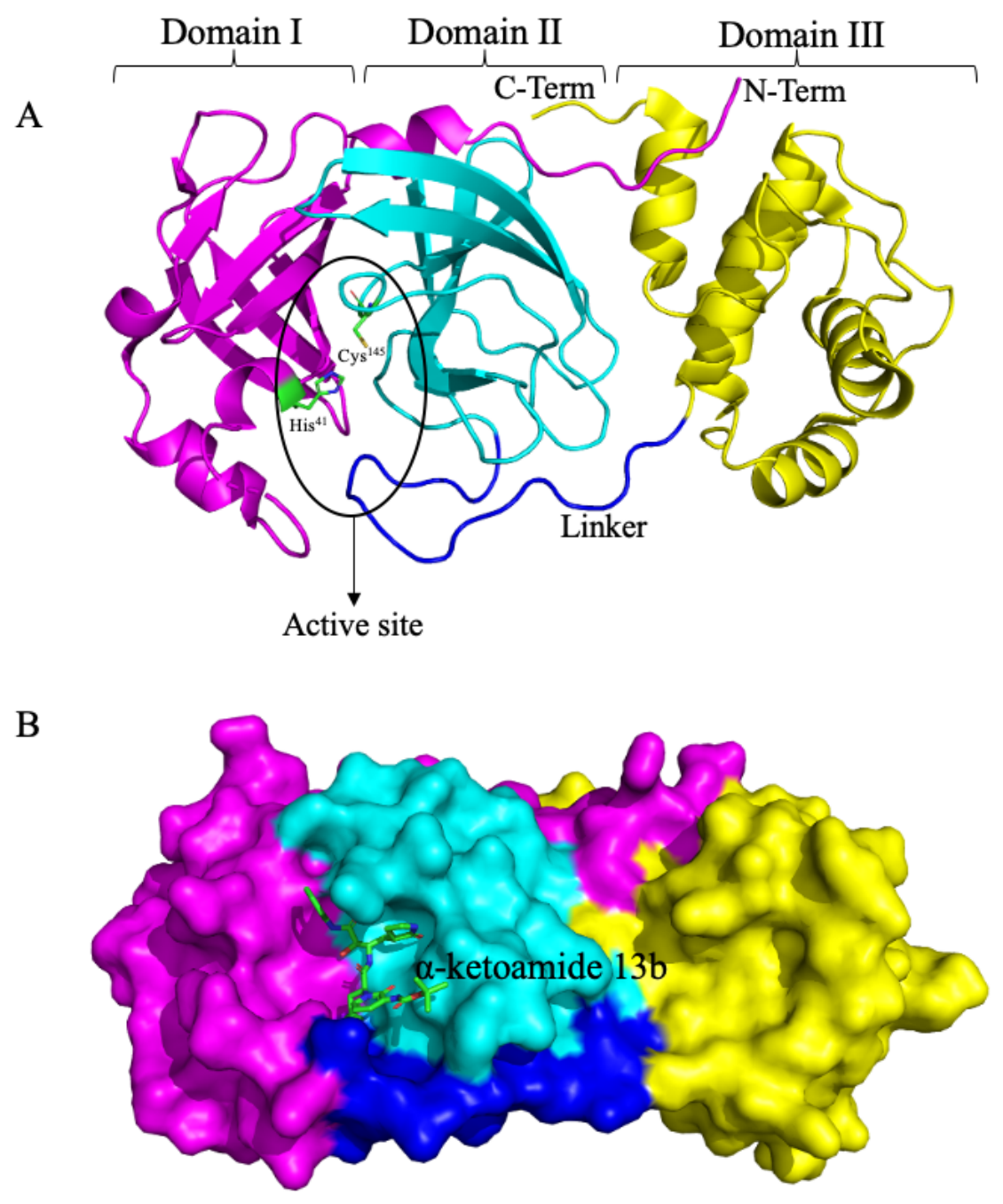

Figure 1. A: Structural features of main protease of SARS-CoV-2 monomer. A SARS-CoV-2 Main protease consist of three domains. The active site of protein lies at the interface of domain I and domain II and composed of a characteristic Cys-His dyad. Domain II is joined by a linker to domain III which is critical for the dimerization of protein.B Sphere representation of Main protease monomer, $\alpha$-ketoamide $13 \mathrm{~b}$ is shown bound in the active site groove.

We have selected a number of existing drugs, most of which are reported to be used in humans for countering certain viral infections and screened them for binding in the active cleft of $\mathrm{M}^{\text {pro }}$. Our results have shown that some of the drugs occupied the active site of $\mathrm{M}^{\text {pro }}$ with even increased binding affinity than that of the bound $\alpha$-ketoamide $13 \mathrm{~b}$. Whilethe rest of the compounds has shown appreciable binding while holding most of the crucial active site 
determinants. We envisage that further in vitro examination of the inhibitory potential of these drugs on the catalytic activity of the main protease could lead the way to repurpose one or more of the tested FDA approved drugs in this study as a treatment therapy for SARS-CoV-2 induced disease.

\section{Materials and methods}

\section{Phylogenetic analysis of SARS-CoV-2 genome}

To understand the evolutionary relationship between the previously known human coronavirus and the novel SARS-CoV-2, we have performed the phylogenetic analysis. For analysis, all the closely related and complete reference genome sequences of SARS-CoV-2 were downloaded from the NCBI GenBank database. A total of 50 genomes were considered for the study. MEGA 6.0 was used for multiple sequence alignment and construction of a phylogenetic tree and 1000 bootstrap replicates is performed using Neighbor-joining method (22).

\section{Molecular docking}

The recently elucidated X-ray crystal structure coordinates of SAR-CoV-2 $\mathrm{M}^{\text {pro }}$ was downloaded from RCSB PDB (PDB ID: $6 \mathrm{Y} 2 \mathrm{~F}$ ), having $1.75 \AA$ resolution (20). In this structure the $\mathrm{M}^{\text {pro }}$ was co-crystallized with the bound improved $\alpha$-ketoamide (13b) inhibitor and multiple intermolecular interaction of ligand with the active site residues are characterized. To further identify the potent inhibitors for SAR-CoV-2 $\mathrm{M}^{\text {pro }}$ among the FDA approved antiviraldrugs, we have downloaded more than 75 drug compounds from the PubChem chemical database. For molecular docking based drug repurposing, the download 3D structures of compounds and protein was prepared. The docking study was performed by AutoDock Vina, which uses a lamrackian genetic algorithm (GA) in combination with grid based energy estimation (23), to check the docking accuracy of software we have performed re-docking to co-crystal bound ligand.The main aim of this molecular interaction study was to identify the highly interacting drug with SAR-CoV-2 protein crystal structure and to propose the drug by in-silico repurposing method. All the interaction visualization analysis studies were performed by Discovery Studio Visualizer (DS), PyMol molecular visualization tool and $\operatorname{LIGPLOT}^{+}(24,25)$. 


\section{Results}

\section{Genome sequence alignment and phylogenetic analysisof SAR-CoV-2}

The sequence alignment of SAR-CoV-2 genome shows high similarity with the closely related reference genomes of other coronaviruses. The Blastn search of the complete genome of SARSCoV-2 reveals that the most closely related virus available in GenBank is SL-CoVZXC45 (MG772933.1) (Bat SARS-like coronavirus) showing 95\% query coverage and $89.11 \%$ identity, whereas another bat SARS-CoV genome SL-CoVZXC21 (MG772934.1) showed 94\% query coverage and $88.65 \%$ sequence identity both isolated from china. Majorly phylogenetic tree was clustered into three clades I, II, and clade III; Clade I consists of 25 SARS-CoV and Bat-SL-CoV complete genome and share sequence identity range from $88.18 \%$ to $100 \%$ when sequencewere aligned using Blastn tool. Whereas Clade II consist of total 12 complete genome of SARS-CoV2 and Bat-SL-CoV, in which 10 genomes are of SARS-CoV-2 which were isolated from patients in different countries [China (MN988668.1, NC_045512.2, MN938384.1, MN975262.1),USA (MN994467.1, MN994468.1, MN985325.1, MN997409.1, MN988713.1) and Nepal (MT072688.1)]. Other two genomes ofBat-SL-CoV were isolated from China (MG772933.1, MG772934.1). In Clade III there are two complete genomes of Bat coronavirus isolated from Germany (GU190215.1) and Kenyan Bat (KY352407.1). Rest of the 11 complete genome of viruses are from Hibicovirus, Nobecovirus, Merbecovirus, and Embecovirus. Importantly,

phylogenetic analysis revealed that there is no divergence in the SAR-CoV-2 genome sequence of different SAR-CoV-2 viruses isolated from different countries during the ongoing outbreak (Fig. 2). 


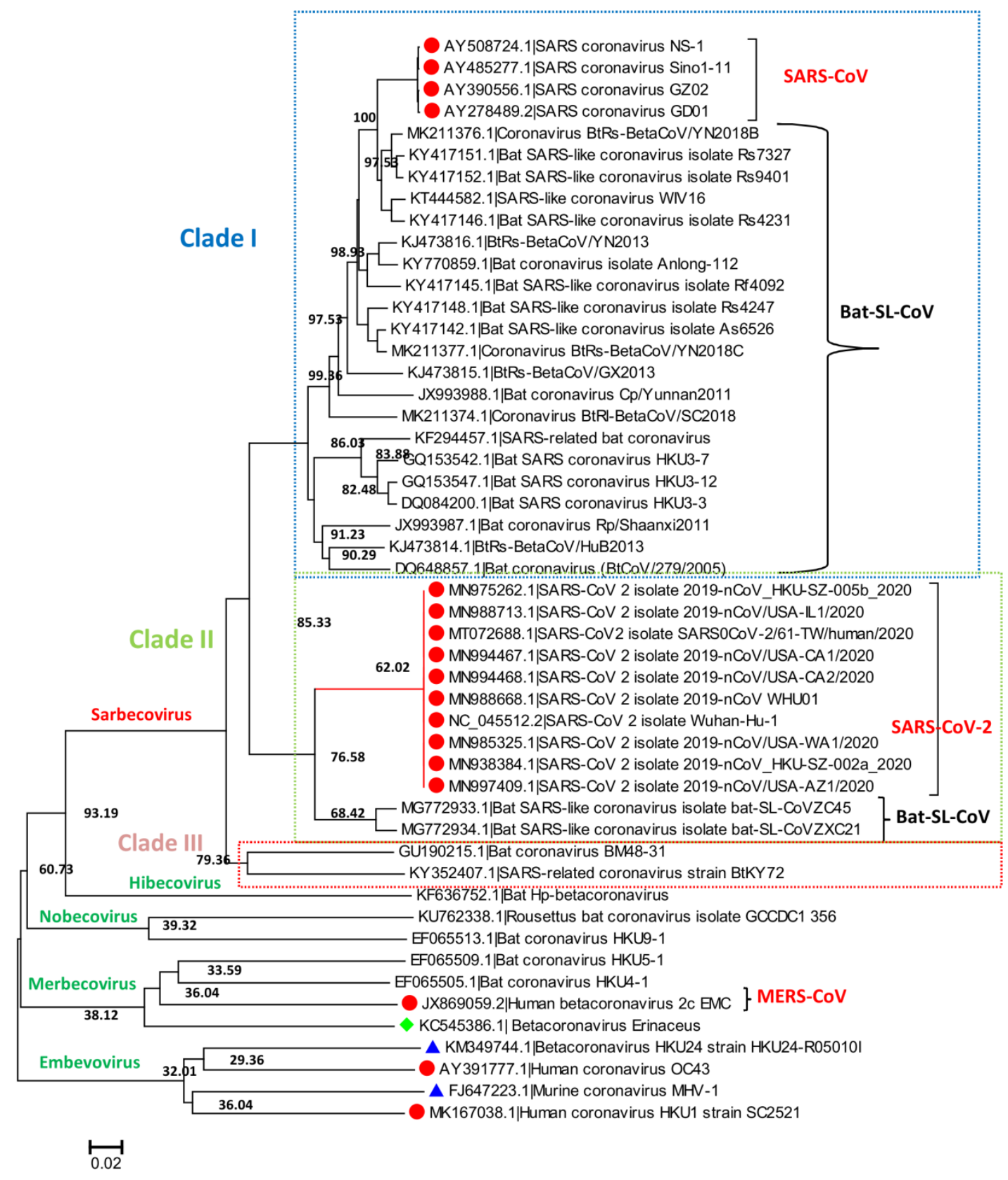

Figure 2. The phylogenetic tree generated for SARS-CoV-2 complete genome, with different neighboring complete genomes of MERS-CoV, SARS-CoV, and Bat-SL-CoV. The tree is majorly showing three clades; clade I, II, and Clade III.

\section{Inhibitor binding cleft of $\mathbf{M}^{\text {pro }}$}

Coronaviruses uses a chymotrypsin like protease along with papain protease to process and cleaves its long polyprotein precursor into individually functional nsPs. Multiple sequence 
analysis of the main protease of SARS-CoV-2 with that of SARS-CoV reveals that amino acid sequence is conserved with a sequence identity of $96 \%$ (Fig. 3). The active site residues are thoroughly conserved and makes a catalytic Cys ${ }^{145}-\mathrm{His}^{41}$ dyad. Additionally there are substrate binding subsites positioned in the active site groove of the protease. The specific subsite residues located in the enzyme active site are named as S1', S1, S2, S3 and S4 depending on their relative position to the cleavage site and subsites P1', P1,P2, P3 and P4 in the polyprotein. Subsite P1 corresponds to the amino acid just before the cleavage site and position P1' corresponds to the residue immediately after the cleavage site. (26-29).

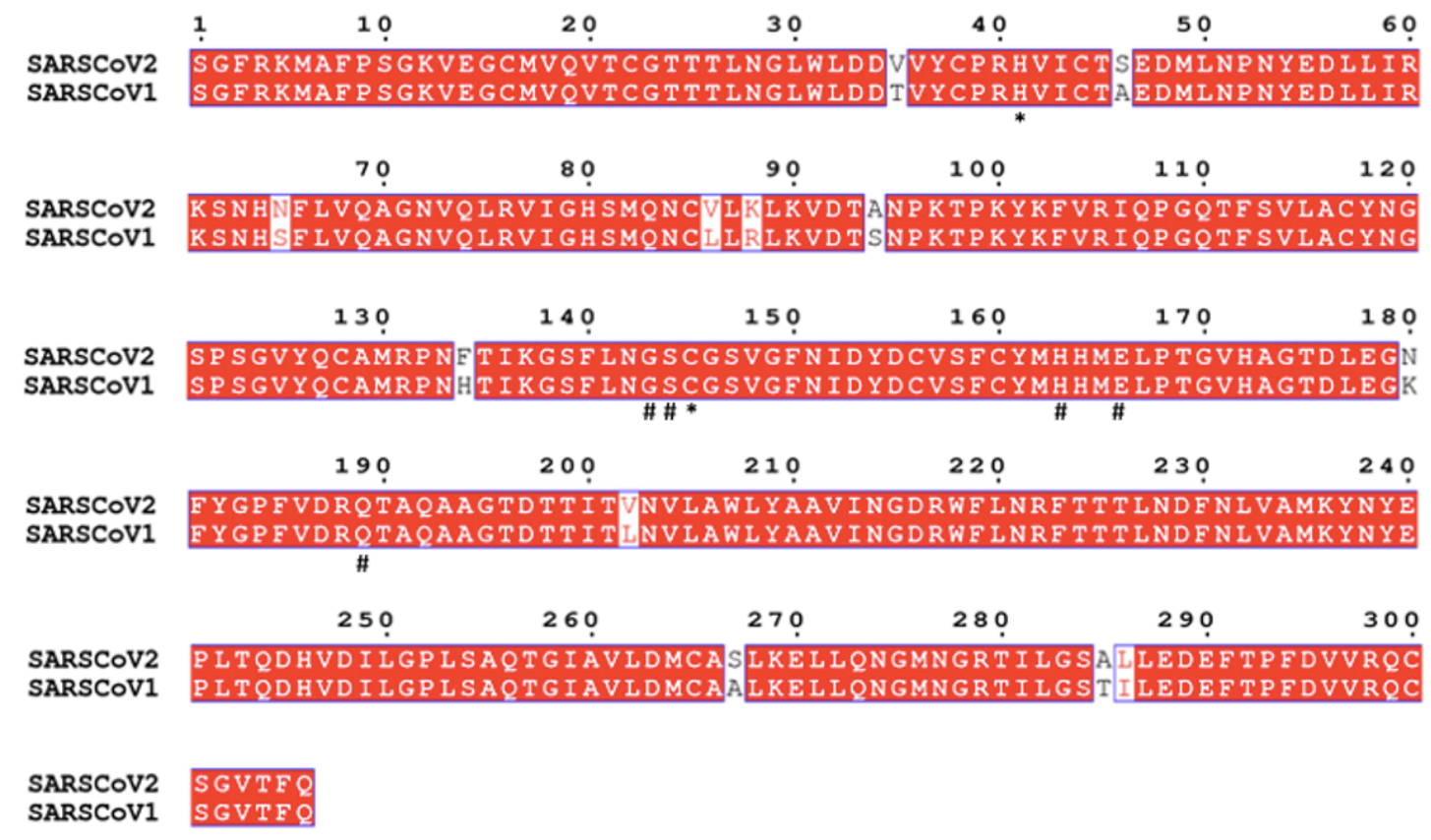

Figure 3. Multiple sequence alignment analysis of amino acid sequence of SARS-CoV-2 Mro. Amino acids marked underneath with * represent the catalytic residues and residues marked underneath with \# represent substrate binding residues of various subsites.

In the $\mathrm{M}^{\text {pro }}$ of SARS-CoV-2 active site region, the $\mathrm{S} 1$ ' residues are contributed by Cys145, Gly143 ans Ser144 which also serve as the oxyanion hole. The S1 residue is His163 while Glu166 \& Gln189 located at the S2 position. Bulky Gln189 and Pro168 makes the S4 site (20) (Fig.4A). The main protease recognizes and bind specific residues at each subsite of the peptide substrate to determine the initiation of proteolysis and production of nsPs for the formation of replication-transcription complex. 

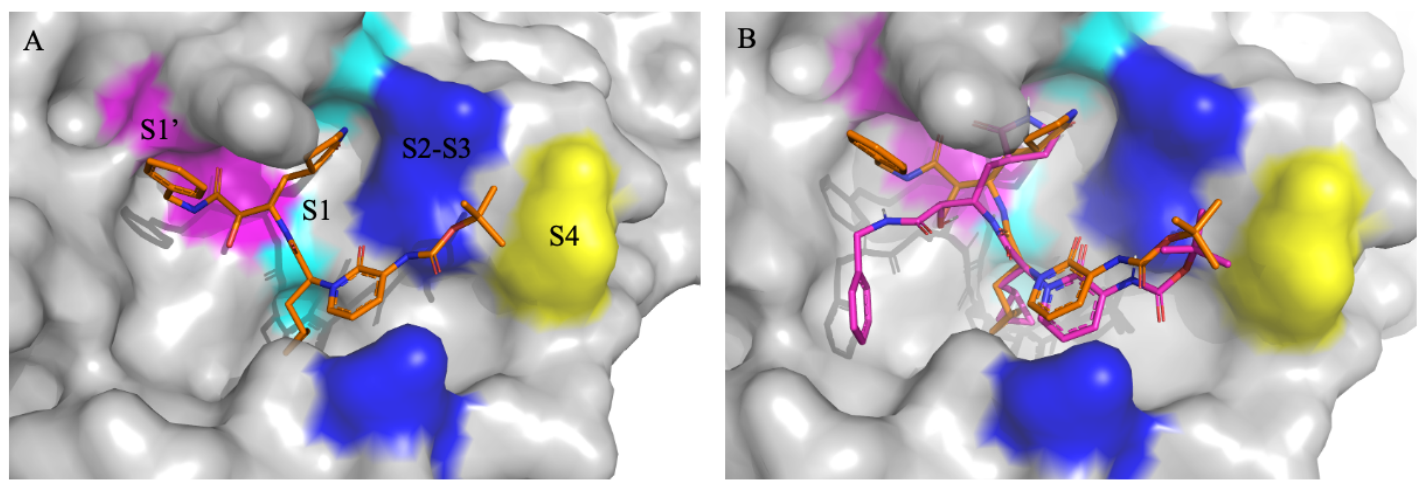

Figure 4. A: Different S1', S1, S2, S3 \& S4 subsites groups in the substrate-binding subsites of SARS-CoV-2M ${ }^{\text {Pro }}$ (PDB ID: 6Y2F). B: Re-docked $\alpha$-ketoamide $13 \mathrm{~b}$ in the active site of $\mathrm{M}^{\text {Pro }}$ (purple) and crystallized $\alpha$-ketoamide (orange).

\section{Docking analysis}

The molecular docking based virtual screening of FDA approved antiviral drugs against the SARS-CoV-2 $\mathrm{M}^{\text {pro }}$ revealed the strong interaction with higher docking energyand binding affinities. All the potential drugs docked with the independent conformation in the active site of protein where the co-crystal structure ligand (improved $\alpha$-ketoamide 13b) bound. Molecular docking binding affinity of all the docked and analysed drugs with their binding energy ranking is shown in table S1 (Supplementary material). The molecular re-docking was also performed to check the docking accuracy of the software AutoDock Vina, and it was observed that the cocrystal bound ligand and re-docked ligand shows RMSD value of $0.51 \AA$, suggesting the high fidelity of docking method (Fig. 4B). In the present study, we focused on the top 10 docking results for further analysis as these drug compounds showing higher binding affinity ranging from $(-10.6$ to $-7.9 \mathrm{kcal} / \mathrm{mol})$. Although among the top 10 drugs,the top three drug compounds were showing binding affinity even higher than that of the improved $\alpha$-ketoamide $13 \mathrm{~b}$ compound (Fig. 5A-D) (Table 1). 

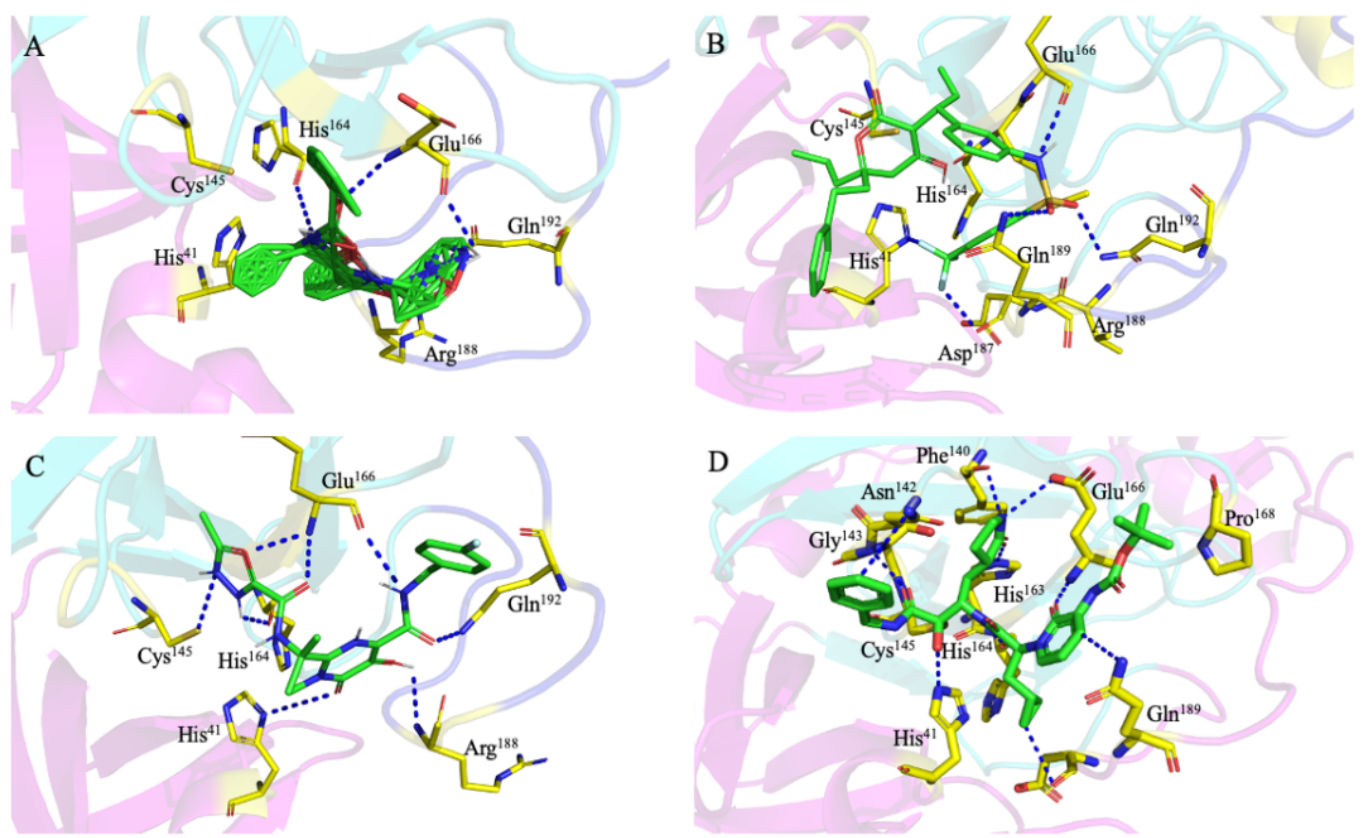

Figure 5. Molecular docking interaction of docked antiviral drugs with SARS-CoV-2 $\mathrm{M}^{\text {pro }}$. A: Lopinavir-Ritonavir. B: Tipranavir. C: Raltegravir and D: Improved $\alpha$-ketoamide (13b). These top three drug compounds show higher binding affinity than the bound $\alpha$-ketoamide compound.

Table 1. Showing the top 10 drug compounds 2-dimensional representation of docking poses interacting with amino acids of target SAR-CoV-2 M ${ }^{\text {pro }}$ (COVID-19) X-ray crystal structure, including co-crystal bound ligand (improved $\alpha$-ketoamide).

\begin{tabular}{|c|c|c|}
\hline $\begin{array}{l}\text { S. } \\
\text { No. }\end{array}$ & $\begin{array}{l}\text { Ligand with a binding } \\
\text { affinity (kcal/mol) }\end{array}$ & Schematic of intermolecular interactions \\
\hline 1. & $\begin{array}{c}\text { Lopinavir-Ritonavir } \\
\text { (-10.6) }\end{array}$ & 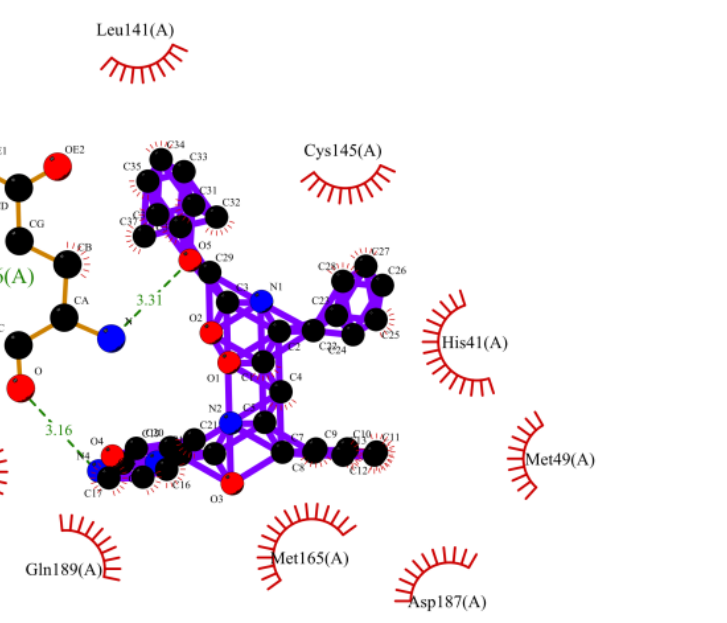 \\
\hline
\end{tabular}




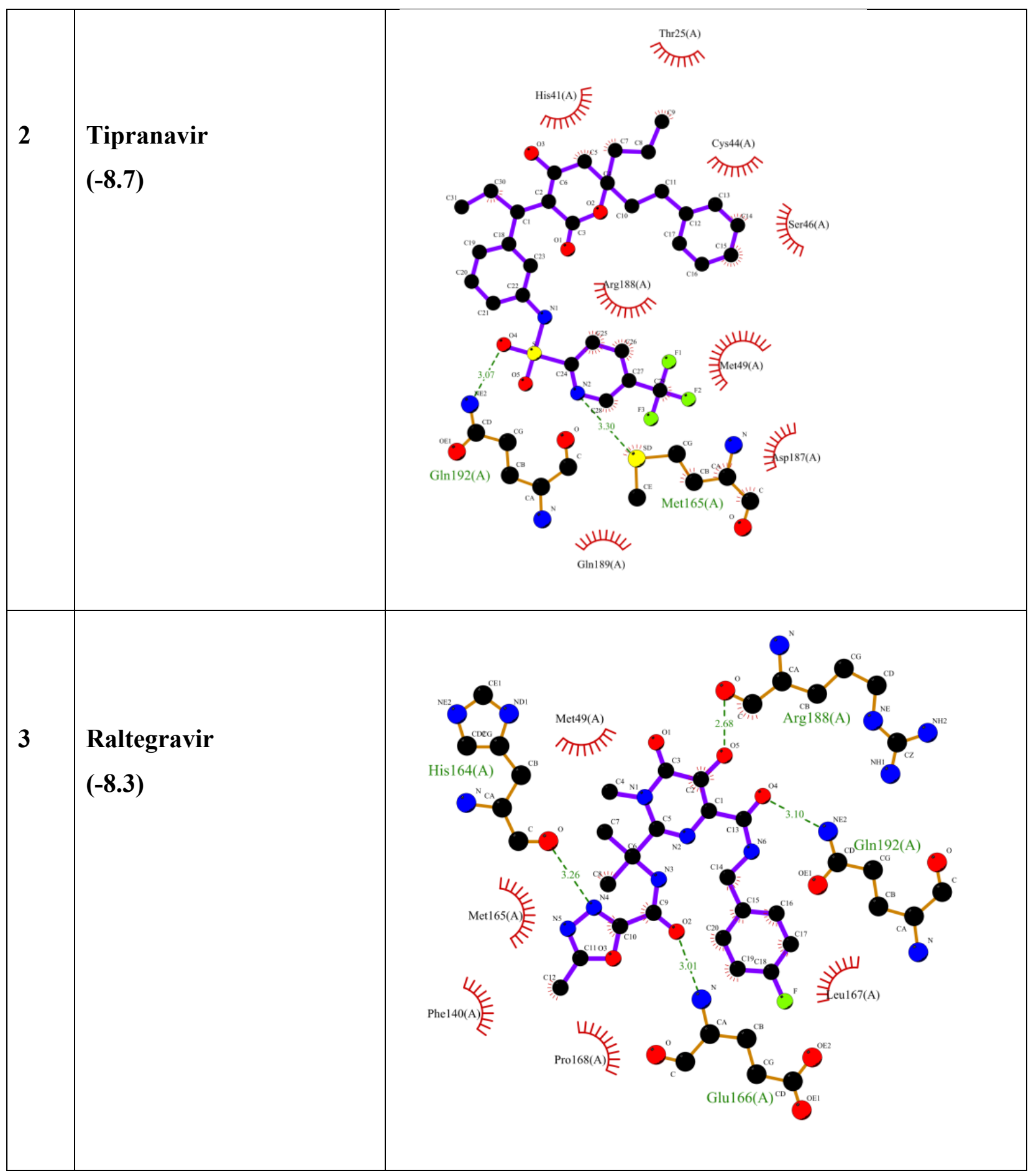




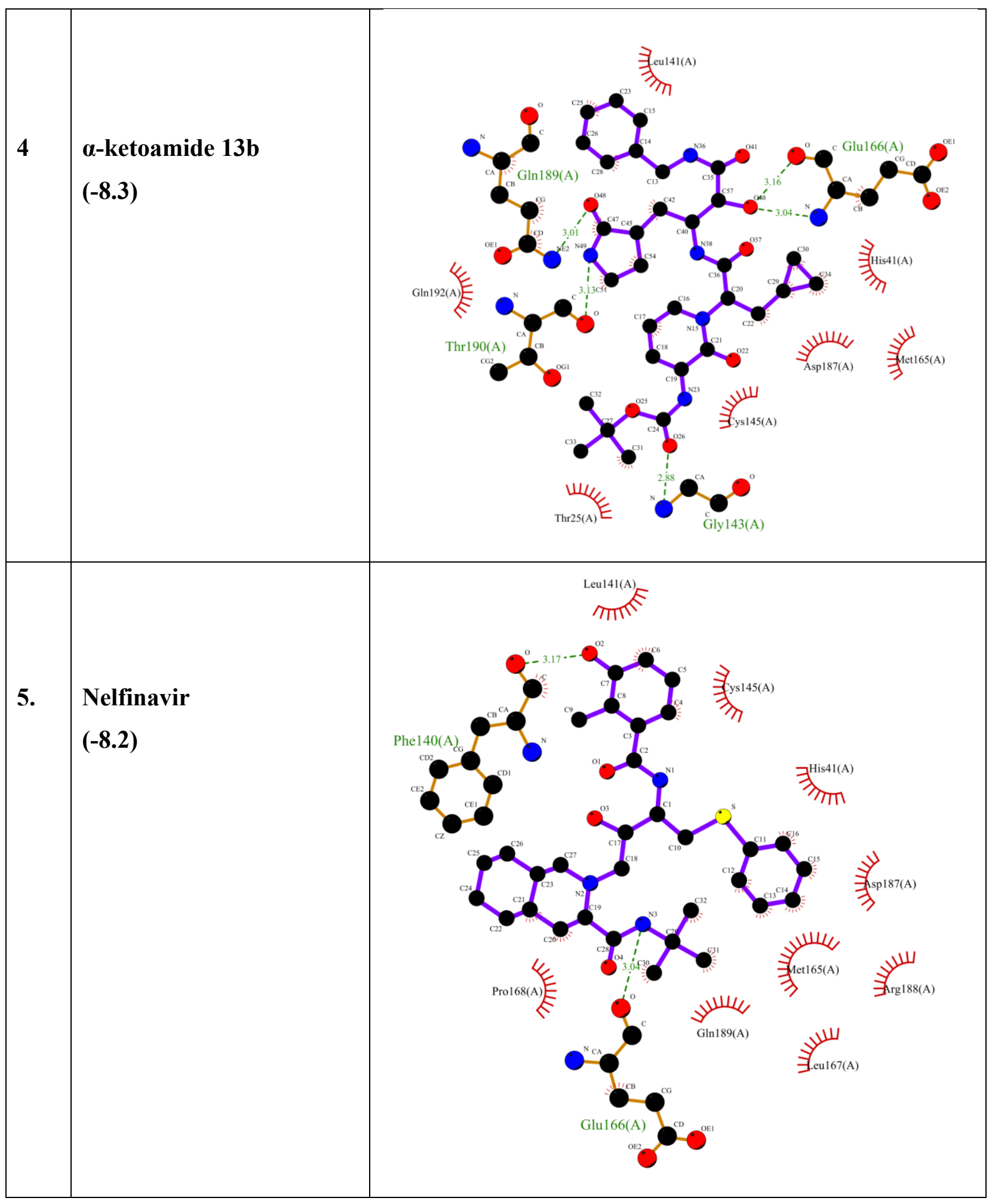




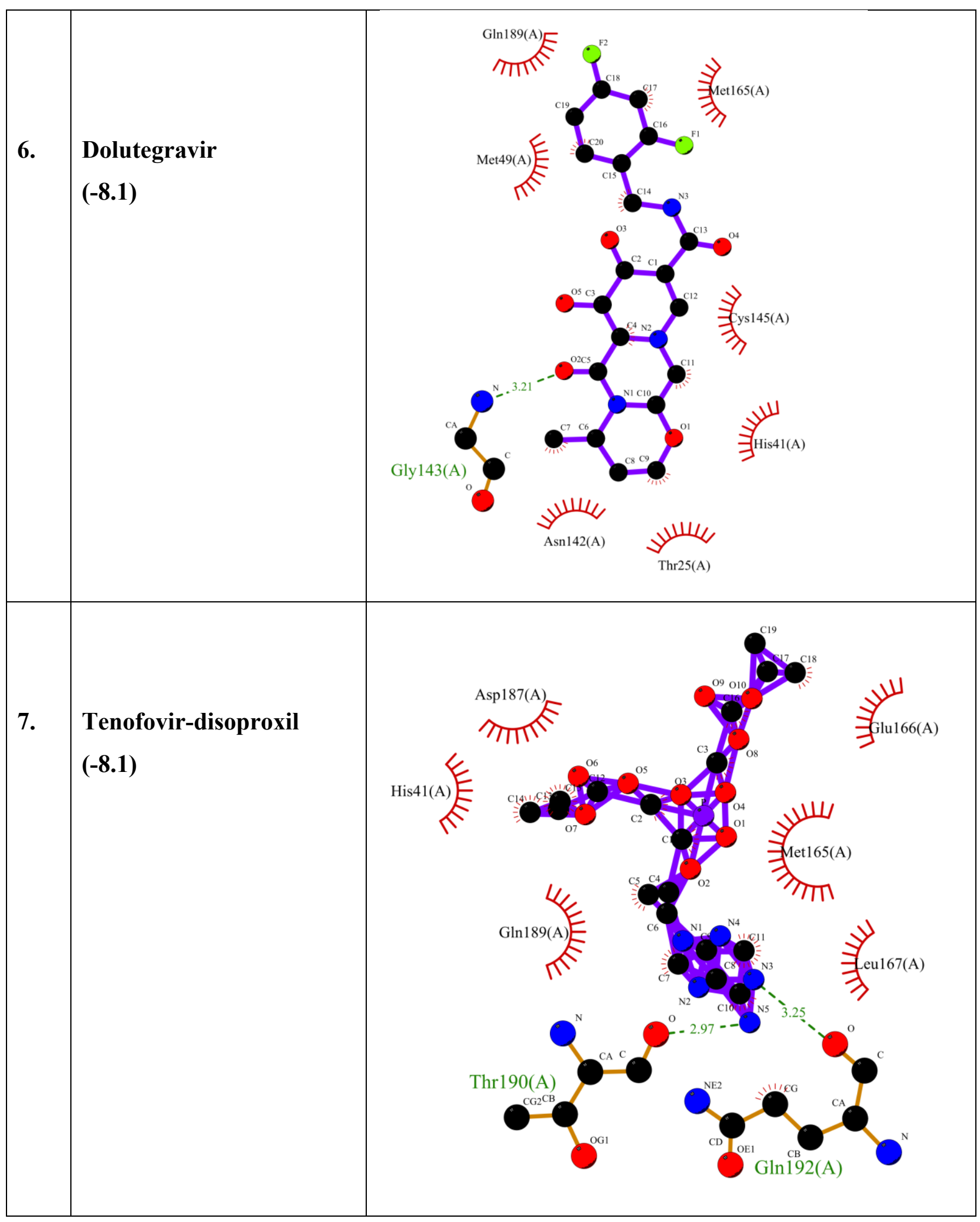




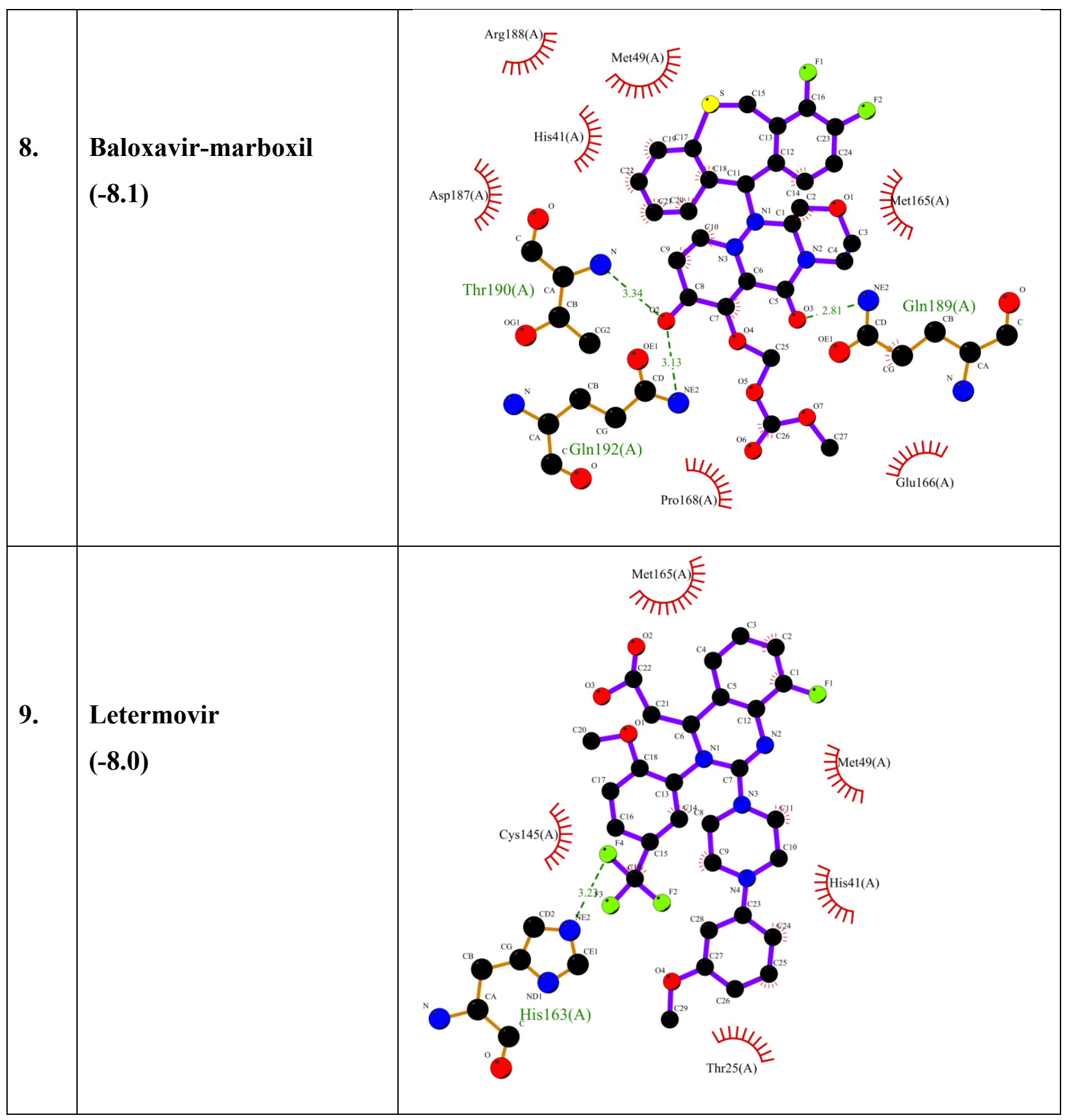




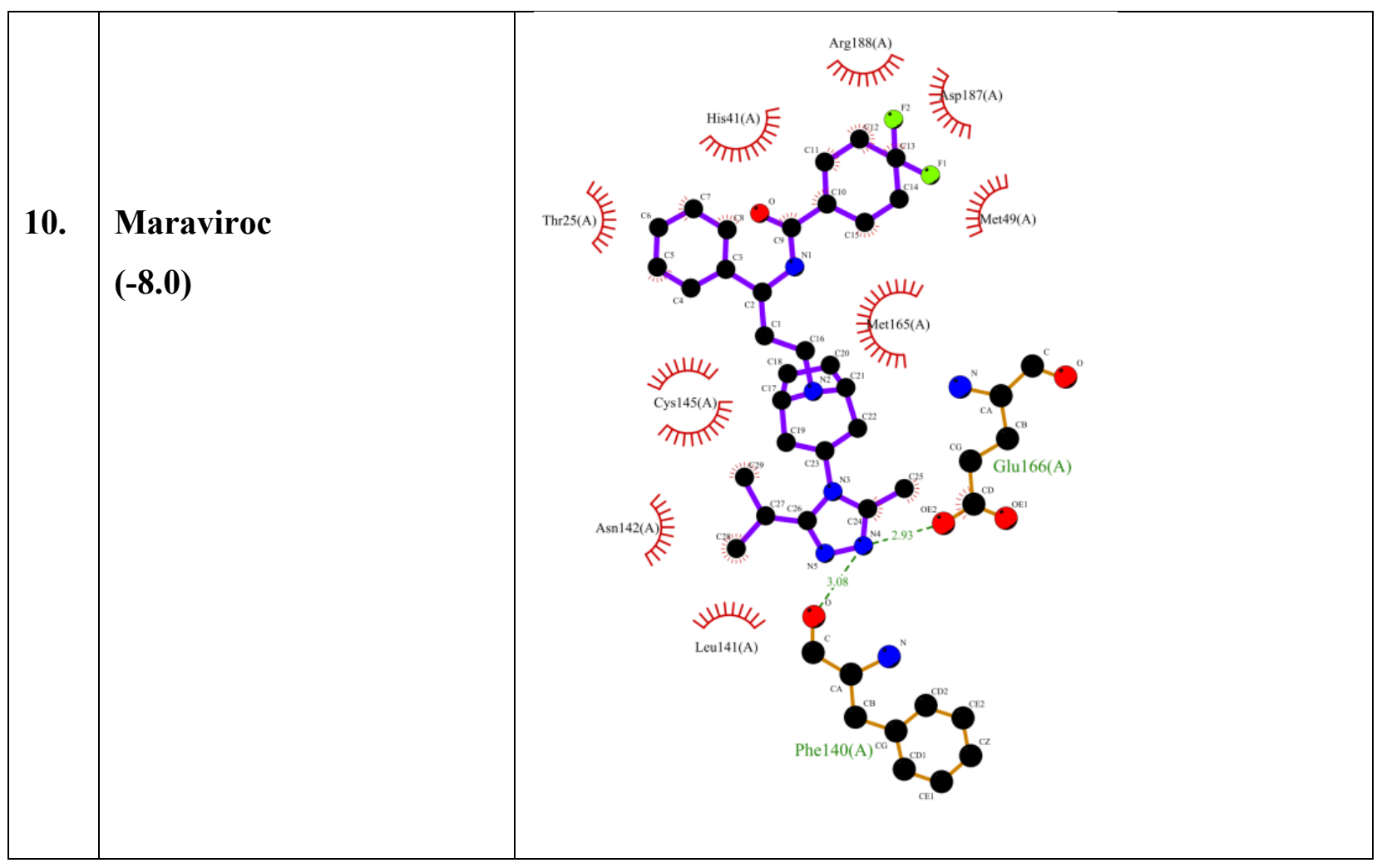

\section{Discussion}

The rapidly spreading disease caused by novel SARS-CoV-2 is now called COVID-19. World Health Organization (WHO) has declared the outbreak a pandemic, which has been increasing exponentially form second week of March, 2020 and has affected nearly all countries around the globe. Although the phylogenetic analysis of different isolates of SARS-CoV-2 from different countries clearly shows that, the SARS-CoV-2 is evolutionarily closely related to the genomes of (SARS-Like Coronavirus) Bat-SL-CoV (the coronavirus present in the bat in China), identified by two independent groups from China. Our study also reveals that it might be possible that SARS-CoV-2 has been originated from Bat-SL-CoV-2 with few mutations, because they share 89.11\% genome identity with SARS-CoV-2.

Till now there is no potent drug or vaccine has been reported or approved to treat the SARS-CoV-2 infected individuals. However, the efforts from the scientific community has been exceptional in advancing research effort towards the development of therapeutic intervention and finding viral drug targets. To that end crystal structure of few of the important viral proteins such as Spike (S) protein and viral papain protease \& chymotrypsin-like protease have been deduced. 
From the recently published studies for SARS-CoV-2 it was observed that virus binds with angiotensin-converting enzymes 2 (ACE2) receptors in the lower respiratory tracts of infected patients to gain entry into the lungs. The study reveals that SARS-CoV-2 main protease (Mro) is the best drug target among coronaviruses (30). Interestingly, one of the most characterized and promising drug targetin against coronavirus infection is the main protease ( $\mathrm{M}^{\text {pro }}$, also known as $3 \mathrm{CL}^{\text {pro }}$ ) which has been co-crystallized with a bound ligand 'improved $\alpha$-ketoamide $13 \mathrm{~b}$ ' in case of SARS-Cov-2 main protease (20,31). This crystal structure reveals that the $\alpha$-ketoamide $13 \mathrm{~b}$ is occupying the active site of the protein and making a number of hydrogen bonds and hydrophobic interactions with the active site residues as well as other substrate binding residues of the binding pocket. In the present study, we have screened more than 75 antiviral, anticancer, and anti-malarial drugs for the identification of potent drug molecules using drug repurposing virtual screening methods. Molecular docking studies have revealed that maximum of the screened drug compounds interact with SARS-CoV-2 $\mathrm{M}^{\text {pro }}$ active pocket and also share same interacting amino acids residues. The SARS-CoV-2 bound ligand (improved- $\alpha$-ketoamide) shows strong bond in interactions with surrounding amino acids within the region of $4 \AA$ at different subsites with His164, Glu166, Gly143, His163, Cys145, His41, and Phe140 where it forms hydrogen bonds with active site His41 and also accept hydrogen bond from the backbone amides of Gly143, Cys145 and Ser144. This protein ligand interaction reveals a strong inhibition of virus protease (Fig. 5D)(20). The screening and molecular docking of at least 75 preexisting drugs we have carried out have shown to fit in the active site of protease in independent conformation and appreciable binding energy score (Fig. 6A-D). Further,we have analyzed and repurposing the top 10 drugs which showed higher or similar binding affinity as compared to the co-crystal bound ligand of SARS-CoV-2. The top 3 drugs that are exhibiting the interaction with same amino acid residues as of the $\alpha$-ketoamide with themain protease are Lopinavir-Ritonavir showing binding affinity of $(-10.6 \mathrm{kcal} / \mathrm{mol})$ and Tipranavir $(-8.7 \mathrm{kcal} / \mathrm{mol})$, whereas Raltegravirhas binding affinity of $(-8.3 \mathrm{kcal} / \mathrm{mol})$, which is similar to improved- $\alpha$-ketomaide $13 \mathrm{~b}$ $(-8.3 \mathrm{kcal} / \mathrm{mol})$. While the rest of the drug compounds have also shown good binding energy score, as presented in table1.

The drug Lopinavir-Ritonavir is a combination product contains two medications lopinavir and ritonavir. This drug is mainly used for HIV-AIDS to control HIV infection by inhibiting the protease and help to decrease the amount of HIV in the body by promoting 
thefunction of body's natural immune system to work better $(32,33)$. The enzyme SARS-CoV-2 $\mathrm{M}^{\text {pro }}$ along with the papain-like proteases is essential for processing the polyproteins into various nonstructural protein by cleaving at specific sites, that are translated from the viral RNA. The interacting amino acids in the $\mathrm{M}^{\text {pro }}$ enzyme active site were reported to be Leu, Gln, Ser, Ala, Glyalong with the Cys-His dyad which marks the cleavage site, similarly our in silico docking study shows that top screened drug Lopinavir-Ritonavir combination interacts with Glu166 (also form strong hydrogen bonding), Gln189, Leu167, Met165, Asp187, Met49, His41, Cys145, and Leu141(Fig.5A).

Table 2. In silico inhibition constant $\left(K_{i}\right)$ obtained by molecular docking for top 10 drugs.

\begin{tabular}{|l|l|c|}
\hline S. No. & Ligands & $\begin{array}{l}\text { In silico inhibition constant } \\
\text { in }\left(\boldsymbol{K}_{i}\right) \text { value in Molar }\end{array}$ \\
\hline 1. & Lopinavir-Ritonavir & $1.6754 \times 10^{-8}$ \\
\hline 2. & Tipranavir & $4.1487 \times 10^{-7}$ \\
\hline 3. & Raltegravir & $8.1265 \times 10^{-7}$ \\
\hline 4. & Improved- $\alpha$-ketoamide $13 \mathrm{~b}$ & $8.1535 \times 10^{-7}$ \\
\hline 5. & Nelfinavir & $9.6539 \times 10^{-7}$ \\
\hline 6. & Dolutegravir & $1.1230 \times 10^{-6}$ \\
\hline 7. & Tenofovir-disoproxil & $1.1430 \times 10^{-6}$ \\
\hline 8. & Baloxavir-marboxil & $1.1435 \times 10^{-6}$ \\
\hline 9. & Letermovir & $1.3533 \times 10^{-6}$ \\
\hline 10. & Maraviroc & $1.3236 \times 10^{-6}$ \\
\hline
\end{tabular}

Interestingly, the binding energy score of Lopinavir-Ritonavir in protein-ligand docking was found to be even better than that of the docked $\alpha$-ketoamide and the in silico inhibition 
constant $\left(K_{i}\right)$ was obtained to be $16 \mathrm{nM}$. In silico inhibition constant $\left(K_{i}\right)$, as obtained by docking is given in table 2 for top 10 drugs.

Drug tipranavir or tipranavir disodium is another nonpeptidic protease inhibitor used in combination with ritonavir to treat HIV infection (34-36). In our study, the drug shows interaction with Gln192, Met165 (both form hydrogen bonding), Gln189, Asp187, Met49, Arg188, Ser46, Cys44, Thr25, and His41 in different conformation from that of $\alpha$-ketoamide inhibitor (Fig. 5B). We hypothesizes that tipranavir or its other derivatives with even improved binding affinity in combination with ritonavir could serve as the potential protease inhibitor to counter SARS-CoV-2 multiplication in cell based assay.
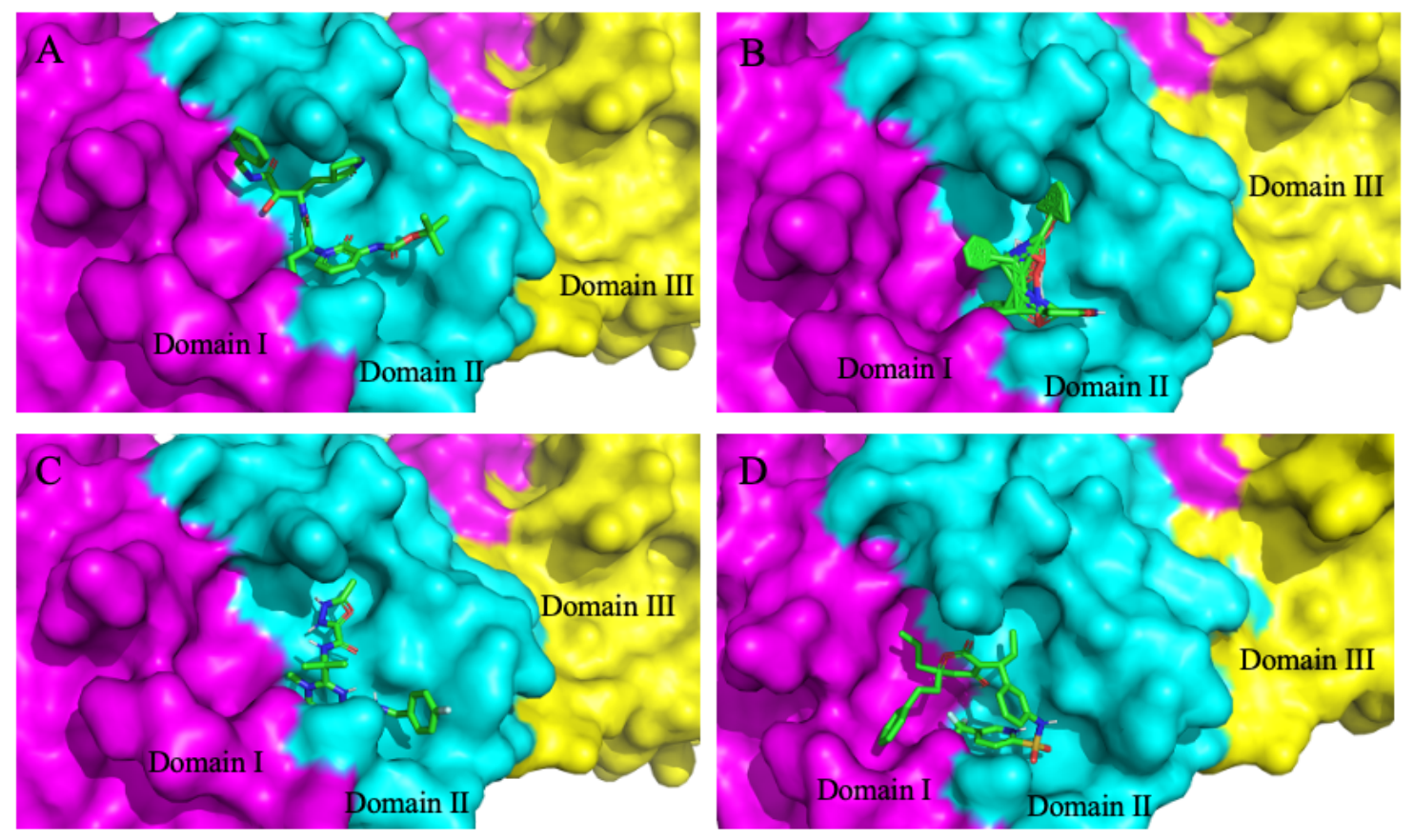

Figure 6. Substrate binding cleft of SARS-CoV-2 $\mathrm{M}^{\text {pro }}$ harboring the docked inhibitors. Top three docked inhibitors. A: Tipranavir, B: Lopinavir-Ritonavir and C: Raltegravir occupy the active site region with independent conformation as the originally $\mathbf{D}$ : bound $\alpha$-ketoamide $13 \mathrm{~b}$ ligand in the co-crystallized structure (PDB ID: 6Y2F).

Another drug which has shown comparable binding affinity and binding energy with that of the docked $\alpha$-ketoamide in $\mathrm{M}^{\text {pro }}$ active site, theraltegraviris a characterized antiretroviral medication which work by inhibiting the integrase strand transfer and is used in combination with other drugs to relieve the HIV infection (37-39). In the present study, raltegravir drug shows 
interaction with His164, Arg188, Gln192, Glu166 (all residues were bonded with strong hydrogen bond), Met49, Met165, Phe140, Pro168, and Leu167. The drug shows four H-bonds with nearest interacting amino acids of SARS-CoV-2 $\mathrm{M}^{\text {pro }}$ enzyme, which indicates good inhibition (Fig. 5C). This drug could also be used with other combinations like raltegravir and lopinavir for the treatment of COVID-19, if found producing desirable inhibitory effect against SARS-CoV-2 protease in biochemical activity assay or cell based assays. Additionally, other drugs which were screened and docked in the substrate binding cleft of the $\mathrm{M}^{\text {pro }}$, has shown good binding energy score which is comparably similar to the original compound in the protein crystal structure. Many of these drugs such as dolutegravir, letermovir \& Nelfinavir are commonly used for treating different infections ranging from HIV to cytomegalovirus by employing different mechanism of action (40-45). The identified repurposed drug and their interaction with binding amino acids in the $\mathrm{M}^{\text {pro }}$ active site have been shown in table 1.

After screening the different FDA approved drugs, the present study enabled us to understand the mode of interaction of approved antiretroviral drugs with new coronavirus SARSCoV-2 main protease enzyme. However, we believe that all the drugs studied and screened for repurposing against COVID-19 in this study should furthermore be tested and their in vitro inhibitory potential needs to be investigated through robust biochemical proteolytic activity assays and other biophysical \& structural studies.

\section{Conclusion}

From this study, we conclude that the repurposed drugs may be helpful for the treatment of novel coronavirus disease and can serve as potential drug candidates to curb the ongoing and everenlarging COVID-19 pandemic. Sinceall the drugs used in this study are of known pharmacokinetics standards and approved by FDA for human use they do not need to undergo specific long term clinical trials and therefore can fasten up the process of the therapeutics development. Our phylogenetic analysis of the available genomes of SARS-CoV-2 isolated from different sources also reveals that the virus is not showing any sign of mutation or diversification rapidly, therefore the repurposed drug combinations could be used against SARS-CoV-2 on pancommunity level. 


\section{Acknowledgment}

YK thank Priyanka Kumari for her useful suggestions and HS thank Petrus Roelofs \& Anjali Malikfor insightful discussions. YK and HS both thanks and appreciate all the researchers and scientists who are working round the clock to deal with COVID-19 pandemic.

\section{Conflict of interest}

Authors declare no conflict.

\section{References:}

1. Chen, N., Zhou, M., Dong, X., Qu, J., Gong, F., Han, Y., Qiu, Y., Wang, J., Liu, Y., Wei, Y. and Yu, T., 2020. Epidemiological and clinical characteristics of 99 cases of 2019 novel coronavirus pneumonia in Wuhan, China: a descriptive study. The Lancet, 395(10223), pp.507-513.

2. Wu, F., Zhao, S., Yu, B., Chen, Y.M., Wang, W., Song, Z.G., Hu, Y., Tao, Z.W., Tian, J.H., Pei, Y.Y. and Yuan, M.L., 2020. A new coronavirus associated with human respiratory disease in China. Nature, 579(7798), pp.265-269.

3. Coronavirus disease 2019 (COVID-19) Situation Report - 65; World Health Organization, Mar29, 2020

4. Cui, J., Li, F. and Shi, Z.L., 2019. Origin and evolution of pathogenic coronaviruses. Nature reviews Microbiology, 17(3), pp.181-192.

5. Fehr, A.R. and Perlman, S., 2015. Coronaviruses: an overview of their replication and pathogenesis. In Coronaviruses (pp. 1-23). Humana Press, New York, NY.

6. Su, S., Wong, G., Shi, W., Liu, J., Lai, A.C., Zhou, J., Liu, W., Bi, Y. and Gao, G.F., 2016. Epidemiology, genetic recombination, and pathogenesis of coronaviruses. Trends in microbiology, 24(6), pp.490-502.

7. Zhou, Y., Hou, Y., Shen, J., Huang, Y., Martin, W. and Cheng, F., 2020. Network-based drug repurposing for novel coronavirus 2019-nCoV/SARS-CoV-2. Cell Discovery, 6(1), pp.1-18.

8. Woo, P.C., Huang, Y., Lau, S.K. and Yuen, K.Y., 2010. Coronavirus genomics and bioinformatics analysis. Viruses 2: 1804-1820.

9. Hussain, S., Chen, Y., Yang, Y., Xu, J., Peng, Y., Wu, Y., Li, Z., Zhu, Y., Tien, P. and Guo, D., 2005. Identification of novel subgenomic RNAs and noncanonical transcription initiation signals of severe acute respiratory syndrome coronavirus. Journal of virology, 79(9), pp.5288-5295.

10. Wong, S.K., Li, W., Moore, M.J., Choe, H. and Farzan, M., 2004. A 193-amino acid fragment of the SARS coronavirus $\mathrm{S}$ protein efficiently binds angiotensin-converting enzyme 2. Journal of Biological Chemistry, 279(5), pp.3197-3201.

11. Hilgenfeld, R., 2014. From SARS to MERS: crystallographic studies on coronaviral proteases enable antiviral drug design. The FEBS journal, 281(18), pp.4085-4096.

12. Zhou, Y., Hou, Y., Shen, J., Huang, Y., Martin, W. and Cheng, F., 2020. Network-based drug repurposing for novel coronavirus 2019-nCoV/SARS-CoV-2. Cell Discovery, 6(1), pp.1-18. 
13. Cui, J., Li, F. and Shi, Z.L., 2019. Origin and evolution of pathogenic coronaviruses. Nature reviews Microbiology, 17(3), pp.181-192.

14. Yang, Y.M., Gupta, S.K., Kim, K.J., Powers, B.E., Cerqueira, A., Wainger, B.J., Ngo, H.D., Rosowski, K.A., Schein, P.A., Ackeifi, C.A. and Arvanites, A.C., 2013. A small molecule screen in stem-cell-derived motor neurons identifies a kinase inhibitor as a candidate therapeutic for ALS. Cell stem cell, 12(6), pp.713-726.

15. Sun, W., Sanderson, P.E. and Zheng, W., 2016. Drug combination therapy increases successful drug repositioning. Drug discovery today, 21(7), pp.1189-1195.

16. Kouznetsova, J., Sun, W., Martínez-Romero, C., Tawa, G., Shinn, P., Chen, C.Z., Schimmer, A., Sanderson, P., McKew, J.C., Zheng, W. and García-Sastre, A., 2014. Identification of 53 compounds that block Ebola virus-like particle entry via a repurposing screen of approved drugs. Emerging microbes \& infections, 3(1), pp.1-7.

17. Johansen, L.M., DeWald, L.E., Shoemaker, C.J., Hoffstrom, B.G., Lear-Rooney, C.M., Stossel, A., Nelson, E., Delos, S.E., Simmons, J.A., Grenier, J.M. and Pierce, L.T., 2015. A screen of approved drugs and molecular probes identifies therapeutics with anti-Ebola virus activity. Science translational medicine, 7(290), pp.290ra89-290ra89.

18. He, S., Lin, B., Chu, V., Hu, Z., Hu, X., Xiao, J., Wang, A.Q., Schweitzer, C.J., Li, Q., Imamura, M. and Hiraga, N., 2015. Repurposing of the antihistamine chlorcyclizine and related compounds for treatment of hepatitis C virus infection. Science translational medicine, 7(282), pp.282ra49-282ra49.

19. Barrows, N.J., Campos, R.K., Powell, S.T., Prasanth, K.R., Schott-Lerner, G., SotoAcosta, R., Galarza-Muñoz, G., McGrath, E.L., Urrabaz-Garza, R., Gao, J. and Wu, P., 2016. A screen of FDA-approved drugs for inhibitors of Zika virus infection. Cell host \& microbe, 20(2), pp.259-270.

20. Zhang, L., Lin, D., Sun, X., Curth, U., Drosten, C., Sauerhering, L., Becker, S., Rox, K. and Hilgenfeld, R., 2020. Crystal structure of SARS-CoV-2 main protease provides a basis for design of improved $\alpha$-ketoamide inhibitors. Science.

21. Yang, H., Yang, M., Ding, Y., Liu, Y., Lou, Z., Zhou, Z., Sun, L., Mo, L., Ye, S., Pang, H. and Gao, G.F., 2003. The crystal structures of severe acute respiratory syndrome virus main protease and its complex with an inhibitor. Proceedings of the National Academy of Sciences, 100(23), pp.13190-13195.

22. Tamura, K., Stecher, G., Peterson, D., Filipski, A. and Kumar, S., 2013. MEGA6: molecular evolutionary genetics analysis version 6.0. Molecular biology and evolution, 30(12), pp.2725-2729.

23. Trott, O. and Olson, A.J., 2010. AutoDock Vina: improving the speed and accuracy of docking with a new scoring function, efficient optimization, and multithreading. Journal of computational chemistry, 31(2), pp.455-461.

24. PyMOL; The PyMOL Molecular Graphics System, Version 2.0 Schrödinger, LLC.

25. Laskowski, R.A. and Swindells, M.B., 2011. LigPlot+: multiple ligand-protein interaction diagrams for drug discovery.

26. Singh, H., Mudgal, R., Narwal, M., Kaur, R., Singh, V.A., Malik, A., Chaudhary, M. and Tomar, S., 2018. Chikungunya virus inhibition by peptidomimetic inhibitors targeting virus-specific cysteine protease. Biochimie, 149, pp.51-61.

27. Narwal, M., Singh, H., Pratap, S., Malik, A., Kuhn, R.J., Kumar, P. and Tomar, S., 2018. Crystal structure of chikungunya virus nsP2 cysteine protease reveals a putative flexible 
loop blocking its active site. International journal of biological macromolecules, 116, pp.451-462.

28. Kiemer, L., Lund, O., Brunak, S. and Blom, N., 2004. Coronavirus 3CL pro proteinase cleavage sites: Possible relevance to SARS virus pathology. BMC bioinformatics, 5(1), p.72.

29. Ton, A.T., Gentile, F., Hsing, M., Ban, F. and Cherkasov, A., 2020. Rapid Identification of Potential Inhibitors of SARS-CoV-2 Main Protease by Deep Docking of 1.3 Billion Compounds. Molecular Informatics.

30. Cao, B., Wang, Y., Wen, D., Liu, W., Wang, J., Fan, G., Ruan, L., Song, B., Cai, Y., Wei, M. and Li, X., 2020. A trial of lopinavir-ritonavir in adults hospitalized with severe Covid-19. New England Journal of Medicine.

31. Anand, K., Ziebuhr, J., Wadhwani, P., Mesters, J.R. and Hilgenfeld, R., 2003. Coronavirus main proteinase (3CLpro) structure: basis for design of anti-SARS drugs. Science, 300(5626), pp.1763-1767.

32. Pulido, F., Arribas, J.R., Delgado, R., Cabrero, E., González-García, J., Pérez-Elias, M.J., Arranz, A., Portilla, J., Pasquau, J., Iribarren, J.A. and Rubio, R., 2008. Lopinavirritonavir monotherapy versus lopinavir-ritonavir and two nucleosides for maintenance therapy of HIV. Aids, 22(2), pp.F1-F9.

33. Delfraissy, J.F., Flandre, P., Delaugerre, C., Ghosn, J., Horban, A., Girard, P.M., Norton, M., Rouzioux, C., Taburet, A.M., Cohen-Codar, I. and Van, P.N., 2008. Lopinavir/ritonavir monotherapy or plus zidovudine and lamivudine in antiretroviralnaive HIV-infected patients. Aids, 22(3), pp.385-393.

34. Doyon, L., Tremblay, S., Bourgon, L., Wardrop, E. and Cordingley, M.G., 2005. Selection and characterization of HIV-1 showing reduced susceptibility to the nonpeptidic protease inhibitor tipranavir. Antiviral research, 68(1), pp.27-35.

35. Turner, S.R., Strohbach, J.W., Tommasi, R.A., Aristoff, P.A., Johnson, P.D., Skulnick, H.I., Dolak, L.A., Seest, E.P., Tomich, P.K., Bohanon, M.J. and Horng, M.M., 1998. Tipranavir (PNU-140690): a potent, orally bioavailable nonpeptidic HIV protease inhibitor of the 5, 6-dihydro-4-hydroxy-2-pyrone sulfonamide class. Journal of medicinal chemistry, 41(18), pp.3467-3476.

36. Larder, B.A., Hertogs, K., Bloor, S., Van den Eynde, C.H., DeCian, W., Wang, Y., Freimuth, W.W. and Tarpley, G., 2000. Tipranavir inhibits broadly protease inhibitorresistant HIV-1 clinical samples. Aids, 14(13), pp.1943-1948.

37. Nachman, S., Zheng, N., Acosta, E.P., Teppler, H., Homony, B., Graham, B., Fenton, T., Xu, X., Wenning, L., Spector, S.A. and Frenkel, L.M., 2014. Pharmacokinetics, safety, and 48-week efficacy of oral raltegravir in HIV-1-infected children aged 2 through 18 years. Clinical infectious diseases, 58(3), pp.413-422.

38. Brainard, D.M., Wenning, L.A., Stone, J.A., Wagner, J.A. and Iwamoto, M., 2011. Clinical pharmacology profile of raltegravir, an HIV-1 integrase strand transfer inhibitor. The Journal of Clinical Pharmacology, 51(10), pp.1376-1402.

39. Blonk, M.I., Colbers, A.P., Hidalgo-Tenorio, C., Kabeya, K., Weizsäcker, K., Haberl, A.E., Moltó, J., Hawkins, D.A., van der Ende, M.E., Gingelmaier, A. and Taylor, G.P., 2015. Raltegravir in HIV-1-Infected Pregnant Women: Pharmacokinetics, Safety, and Efficacy. Clinical infectious diseases, 61(5), pp.809-816.

40. Gills, J.J., LoPiccolo, J. and Dennis, P.A., 2008. Nelfinavir, a new anti-cancer drug with pleiotropic effects and many paths to autophagy. Autophagy, 4(1), pp.107-109. 
41. Kirby, B.J., Collier, A.C., Kharasch, E.D., Whittington, D., Thummel, K.E. and Unadkat, J.D., 2011. Complex drug interactions of HIV protease inhibitors 1: inactivation, induction, and inhibition of cytochrome P450 3A by ritonavir or nelfinavir. Drug metabolism and disposition, 39(6), pp.1070-1078.

42. Walmsley, S.L., Antela, A., Clumeck, N., Duiculescu, D., Eberhard, A., Gutiérrez, F., Hocqueloux, L., Maggiolo, F., Sandkovsky, U., Granier, C. and Pappa, K., 2013. Dolutegravir plus abacavir-lamivudine for the treatment of HIV-1 infection. New England Journal of Medicine, 369(19), pp.1807-1818.

43. Cottrell, M.L., Hadzic, T. and Kashuba, A.D., 2013. Clinical pharmacokinetic, pharmacodynamic and drug-interaction profile of the integrase inhibitor dolutegravir. Clinical pharmacokinetics, 52(11), pp.981-994.

44. Marty, F.M., Ljungman, P., Chemaly, R.F., Maertens, J., Dadwal, S.S., Duarte, R.F., Haider, S., Ullmann, A.J., Katayama, Y., Brown, J. and Mullane, K.M., 2017. Letermovir prophylaxis for cytomegalovirus in hematopoietic-cell transplantation. New England Journal of Medicine, 377(25), pp.2433-2444.

45. Lischka, P., Michel, D. and Zimmermann, H., 2016. Characterization of cytomegalovirus breakthrough events in a phase 2 prophylaxis trial of letermovir (AIC246, MK 8228). The Journal of infectious diseases, 213(1), pp.23-30. 